\title{
Effects of Resistance Training and Whole-Body Electromyostimulation on Muscular Strength in Female Collegiate Softball Players
}

\author{
Raja Nurul Jannat Raja Hussain ${ }^{1 *}$ and Maisarah Shari ${ }^{2}$ \\ ${ }^{1}$ Department of Sports Science, Faculty of Sports Science and Recreation, Universiti Teknologi MARA Seremban \\ 70300, Negeri Sembilan, Malaysia \\ ${ }^{2}$ Department of Physical and Health, Faculty of Education, Universiti Teknologi MARA, Puncak Alam 42300, \\ Selangor, Malaysia
}

\begin{abstract}
Strength and conditioning coaches frequently use traditional resistance training (TRT) to build strength. However, in recent years, whole-body electromyostimulation (WB-EMS) was used in elite athletes to increase muscle strength. This study aimed to assess the effect of two different types of training on muscular strength. Sixty female collegiate players $($ Age $=23.52 \pm 1.89$ years, Height $=156.20 \pm 1.71 \mathrm{~cm} ;$ Mass $=53.21 \pm 3.17 \mathrm{~kg})$ participated in this study and were randomly assigned to three training groups. All groups trained as usual for eight weeks, except for the first group, which received additional TRT. The second group received additional electrical stimulation training, and the third group did not receive any additional training following the regular softball bat swing training. Muscular strength (upper and lower body) was assessed by a 3RM bench press and a 3RM squat test before and after the eight-week programme. The primary findings indicate that after eight weeks of training, upper body and lower body strength increased significantly in both the TRT and WB-EMS groups ( $p=0.000$ and $p=0.000$, respectively) in comparison to the control group. However, the $t$ value indicated that the TRT group improved both upper body strength (20.18) and lower body strength (29.18) more than the WB-EMS group (upper body $=6.18$; lower body $=6.47$ ). The findings demonstrate the efficacy of both

ARTICLE INFO

Article history:

Received: 15 June 2021

Accepted: 27 July 2021

Published: 24 September 2021

DOI: https://doi.org/10.47836/pjssh.29.3.24

training modalities for increasing muscular strength and suggest that TRT be prioritised over whole-body electrical stimulation training for increasing muscular strength in collegiate softball players.
\end{abstract}

$\overline{\text { E-mail addresses: }}$

nuruljannat@uitm.edu.my (Raja Nurul Jannat Raja Hussain)

maisarahshari@uitm.edu.my (Maisarah Shari)

* Corresponding author
Keywords: Electromyostimulation, intensity, softball, strength 


\section{INTRODUCTION}

Softball can be regarded as a popular recreational and competitive sport played commonly by women and men worldwide. This sport requires complex skills such as running, throwing, catching, pitching, and batting. These skills require accuracy, speed, and strength (Milanovich \& Nesbit, 2014; Park et al., 2020). Therefore, many conditioning coaches seek an optimal training programme to improve softball skills and performance. One of the training programmes is resistance training, which has been noted to be an eminent method for increasing muscular strength, particularly the main muscles used in softball (arms, chest, core, thigh, and glutes) (DeRenne et al., 2001; Stuempfle et al., 2004). Following a resistance training programme, these studies also found more outstanding performance in throwing, pitching, and batting among softball players.

Resistance training has been commonly used for the last 30 years to improve muscular strength in school, amateur, and professional athletes (Nunes et al., 2021; Stricker et al., 2020; Szymanski et al., 2009; Szymanski, McIntyre et al., 2007). A traditional resistance training (TRT) session lasts up to 60 minutes (Moro et al., 2020). However, coaches have limited time to train their athletes (Ludwig et al., 2020). For example, an average, a college softball team has a maximum of 20 hours of training time, in which skill and conditioning practices need to be allocated. If a team takes two-and-a-half hours to do skill practice on each typical six-day training schedule, they will have only five hours of conditioning practice each week. As a result, they frequently overlook conditioning practice to concentrate on game techniques and tactics. Time is a crucial factor to the coaches; it contributes to players having an undermanned strength base, which subsequently deteriorates their athletic performance (Sugimoto et al., 2017).

Therefore, a time-saving training programme comprising high-efficiency muscle adaptation stimulus can be favourable to coaches. One of the alternative training approaches available is muscle stimulation through electromyostimulation (EMS), which appears to be promising for developing and improving fundamental strength capacities (such as sprinting and jumping) and increasing athletes' maximal strength (Bhave, 2021; Billot et al., 2010; Filipovic et al., 2016; Gondin et al., 2006; Strasunskas, 2020). The stimulation of muscles with electrodes applied to the skin has been recognised of physical therapy for a long time (Ludwig et al., 2020). Filipovic et al. (2012) demonstrated that EMS could also be used in sports to enhance training and individual strength abilities (e.g., maximal strength, speed-strength, and power). The method increased neuromuscular muscle fibre recruitment and muscular adaptations, such as muscle fibre change or hypertrophy (Maffiuletti et al., 2006). Therefore, the EMS can be a pleasant addition to traditional athletic training.

Gregory and Bickel (2005) found that electrical stimulation had caused more indirect involuntary contractions 
mediated by the central nervous system. Low-frequency (approximately 50-120 Hz) EMS has been shown to increase muscle tension, resulting in increased metabolic and mechanical stress on the muscular structures, hence triggering neuronal and hormonal adaptation processes (Gregory \& Bickel, 2005; Jubeau et al., 2008; Nosaka et al., 2011). Numerous studies on the effects of EMS on athletes also found a significant increase in strength (Dehail et al., 2008; Filipovic et al., 2019; Ludwig et al., 2020) after EMS training. Babault et al. (2007) reported a significant increase in strength and power for selected muscles (quadriceps femoris, gluteus maximus, and triceps) over a 12-week training period. However, such improvements did not benefit rugby's technical skills, such as scrummaging and sprinting. In one study by Herrero et al. (2006), a combination of EMS and plyometric training improved quadriceps femoris maximal strength, vertical jump, and sprint. However, the same study also found that electrostimulation alone did not decrease sprint velocity and that its benefits were not greater than those observed when combined with plyometric training.

Previous studies (Jubeau et al., 2008; Nosaka et al., 2011; Sanchez et al., 2005) have applied a single electrode EMS to specific muscles. However, the new generation of whole-body EMS (WBEMS) device allowed for simultaneous training of multiple muscle groups via an electrode belt and vest system. Other studies had found that when WB-EMS stimulation was performed with isometric contraction and at maximum contraction, the chances of muscular damage may increase (Kemmler \& von Stengel, 2013; Stöllberger \& Finsterer, 2019). Therefore, adjusting to the intensity of training while on WB-EMS is challenging. When not used properly, WB-EMS exercises can result in health risks hence questioning the benefit of this training mode. Accordingly, recent studies sought to examine the effects of WBEMS on health parameters and efficiency (Filipovic et al., 2016, 2019; Kemmler et al., 2018), and recommendations for a safe and efficient implementation were proposed (Hussain et al., 2016, Kemmler et al., 2018). However, it is widely recognised that when WB-EMS training is correctly implemented and monitored, it can be a safe method of developing physical performance and wellbeing in healthy adults and athletes.

EMS can be advantageous to coaches with limited physical conditioning training time available. However, only a few studies were conducted on athletes using the WB-EMS approach compared to studies concerning the use of a single electrode EMS (Filipovic et al., 2016). Previous studies concerning the WB-EMS use primarily concern trainings for increasing muscle mass and reducing abdominal fat (Kemmler \& von Stengel, 2013) and energy expenditure (Kemmler et al., 2012) among sedentary and older women. Another study sought to improve resting metabolic rate and body composition (Kemmler et al., 2010). However, little has been explored on the effects of WB-EMS on general fitness performance, such as muscle strength. 
Given the knowledge gap, the current study seeks to compare the effects of TRT on the muscular strength of female college softball players in a WB-EMS programme. Female players were selected because compared to the male softball teams, the Malaysian women's softball teams have more potential to excel in the future following their consistent participation in the Southeast Asian Games.

\section{METHODS}

\section{Participants}

Eighty volunteer female softball players came for screening. However, twenty of them did not meet the inclusion criteria, leaving sixty healthy female collegiate softball players (age: $M=23.52, S D=1.89$ years old, height: $M=156.20, S D=1.71$ cm, weight: $M=53.21, S D=3.17 \mathrm{~kg}$ ) for recruitment (Figure 1). The inclusion criteria were as follows: (i) must be in the official collegiate softball team roster, (ii) have experience in resistance training, and (iii) have no self-reported sickness, neurological problems, mental illness, or significant current and past injuries that could place them at risk while performing exercises and training. In addition, all participants were tested on their upper-lower body strength. As a result, showed no differences in their strength test, a fish-bowl technique was used to randomly assign them into three groups (TRT, WB-EMS, CTR), each comprising

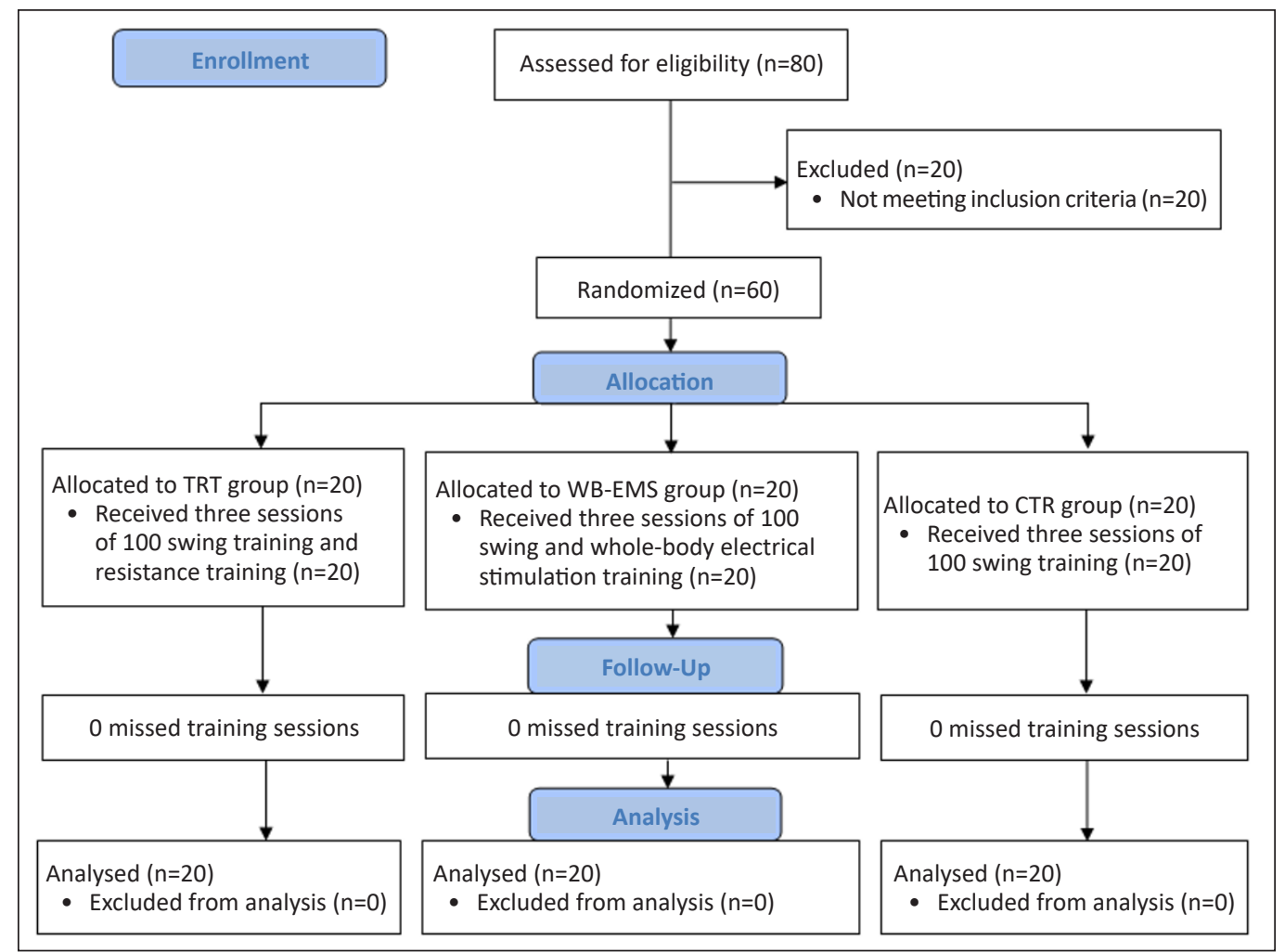

Figure 1. CONSORT 2010 flow diagram 
20 participants. This study was approved by the Research Ethics Committee, Universiti Teknologi MARA (600-RMI 5/1/6).

\section{Experimental Design and Procedures}

The effects of interventions on muscular strength were measured using a randomised pretest-posttest control group design. The players' muscular strengths were measured using three rounds of repetition maximum (3RM) bench press and squat tests. Multiplerepetition tests are known to be a reliable, valid, and safe method for predicting 1RM among beginners and intermediate athletes (Ruivo et al., 2016) with a validity value of $r=0.84-0.92$. The procedure and guideline for conducting both tests were retrieved from National Strength and Conditioning Association (NSCA) and Earle et al. (2004). Bryzcki's equation was used to calculate the estimated 1RM of all the players (Ruivo et al., 2016).

\section{Testing Procedures}

3RM Bench Press. The participants performed full-body dynamic warm-up exercises prior to the $3 \mathrm{RM}$ bench press test. Then, a specific warm-up of 5 to 10 repetitions with a light to moderate load was applied. The test was conducted using an Olympic barbell (15-20 kg) and a flat bench. Following the warm-up, a 1-minute rest period was given. Next, a range from 4 to $9 \mathrm{~kg}$ of the load was added, and the players were allowed to complete 3 to 5 repetitions. Then, a 4-minute rest was provided before the load was increased to the player's nearmaximal-load ability, and they were allowed to complete 3 repetitions. If the player successfully pressed for three repetitions, a 3-minute rest was given, and then the load was increased. Then, the player re-attempted the 3RM. If she failed, a 3-minute rest was given, and the load was decreased by 2 to $4 \mathrm{~kg}$. Then, the player re-attempted the 3RM. Adding and decreasing the load was repeated until the player completed the $3 \mathrm{RM}$ with the proper technique. Ideally, the 3RM was measured within 3 to 5 testings (Baechle \& Earle, 2008).

3RM Squat. Following the 3RM bench press test, the participants performed a specific warm-up of 5 to 10 repetitions with light to moderate load. The test was conducted using an Olympic barbell (15-20 $\mathrm{kg}$ ) and a squat rack. Following the warmup, a 1-minute rest period was given. Next, a range from 14 to $18 \mathrm{~kg}$ of the load was added, and the players were allowed to complete 3 to 5 repetitions. Then, a 4-minute rest was provided before the load was increased to the player's near-maximal-load ability, and they were allowed to complete 3 repetitions. If the player successfully pressed for three repetitions, a 3-minute rest was given, and then the load was increased. Then, the player was asked to re-attempt the 3RM. If she failed, a 3-minute rest was given, and the load was decreased by 7 to 9 $\mathrm{kg}$. Then, the player was asked to re-attempt the 3RM. Adding and decreasing the load was repeated until the player completed the 3RM with the proper technique. Ideally, the 3RM was measured within 3 to 5 testings (Baechle \& Earle, 2008). 
Training Intervention. Three training groups were involved in this study. The training frequency for all the training groups was 3 days per week (Monday, Wednesday, Friday), and the duration of each session was varied based on the type of training. The first group was a TRT group, which consisted of 20 players. This group was asked to perform resistance exercises after a normal-swing training session (Table 1). The normal-swing training was divided into 5 sets, with 20 swings per set, and all the players were told to use the same bat (DemaRini; 34-inch; 24-Oz) for the entire eight-week training. The resistance training was performed in the gym using free weights, dumbbells, and machines. The training was planned according to a stepwise periodised method for improving muscular strength in baseball and softball players (Stone et al., 2000; Szymanski, Szymanski et al., 2007; Szymanski et al., 2004). Progressive overload was implemented in this training in which all the exercises began with high repetition, low intensity (low volume) to low repetitions, and high intensity (high volume). Sixty-five per cent of the estimated 1RM was set for the first week and increased by 5\% (as tolerated) for each week of training until it reached $80 \%$ of $1 \mathrm{RM}$ at week four. Then, at the end of the fourth week, the 3RM testing was repeated to determine a new predicted $1 \mathrm{RM}$. The intensity started at $85 \%$ of the predicted 1RM for the following week, i.e. the fifth week, and was increased by $5 \%$ from the sixth to the eighth week. If, the participant could complete more

Table 1

Resistance training programme

\begin{tabular}{|c|c|c|c|c|c|c|}
\hline \multirow[t]{2}{*}{ Variables } & \multicolumn{3}{|c|}{ Week 1 to week 4} & \multicolumn{3}{|c|}{ Week 5 to week 8} \\
\hline & \multicolumn{2}{|c|}{ Sets } & Reps & \multicolumn{2}{|c|}{ Sets } & Reps \\
\hline Warm-up & \multicolumn{2}{|c|}{2} & 10 & \multicolumn{2}{|c|}{2} & 10 \\
\hline \multirow[t]{2}{*}{ Swing practice } & \multicolumn{2}{|c|}{5} & 20 & \multicolumn{2}{|c|}{5} & 20 \\
\hline & Sets & Reps & $\% \mathrm{RM}$ & Sets & Reps & $\% \mathrm{RM}$ \\
\hline Warm-up & 2 & 10 & $50-60$ & 2 & 10 & $50-60$ \\
\hline Parallel squat & 3 & $6-8$ & $65-80$ & 3 & $2-6$ & $85-90$ \\
\hline Stiff leg deadlift & 3 & $6-8$ & $65-80$ & 3 & $2-6$ & $85-90$ \\
\hline Barbell bench press & 3 & $6-8$ & $65-80$ & 3 & $2-6$ & $85-90$ \\
\hline Triceps push down & 2 & $10-12$ & $50-65$ & 2 & $8-12$ & $70-75$ \\
\hline Dumbbell biceps curl & 2 & $10-12$ & $50-65$ & 2 & $8-12$ & $70-75$ \\
\hline Seated Row & 2 & $10-12$ & $50-65$ & 2 & $8-12$ & $70-75$ \\
\hline Weighted Ball Exercise & Sets & Reps & Load $(\mathrm{kg})$ & Sets & Reps & Load $(\mathrm{kg})$ \\
\hline Hitters throw & 2 & 6 & 5 & 2 & 8 & 4 \\
\hline Standing figure 8 & 2 & 6 & 5 & 2 & 8 & 4 \\
\hline Speed rotation & 2 & 6 & 5 & 2 & 8 & 4 \\
\hline Standing side throw & 2 & 6 & 5 & 2 & 8 & 4 \\
\hline Squat and throw & 2 & 6 & 5 & 2 & 8 & 4 \\
\hline
\end{tabular}

Note. Reps $=$ Repetitions, $\% \mathrm{RM}=$ percentage of repetition maximum 
than the prescribed repetitions during the eighth week of training, the intensity was gradually increased. If the individual could not complete the repetitions, the load was reduced by the smallest amount possible in the subsequent exercise session. The TRT group took approximately 1 hour and 30 minutes to complete both swing and resistance training in each exercise session.

The second group was the wholebody electromyostimulation (WB-EMS) group, which consisted of 20 players who performed an electrical stimulation exercise after a normal-swing training session (Table 2 ). The group performed the exercise in a studio using a whole-body electrical stimulation machine (miha-boodytec, Augsberg, Germany). The application unit was connected via electrical cords to a stimulation vest and belts (Figure 2). Bilaterally paired surface electrodes were integrated. Eight muscle areas could be stimulated synchronously with freely

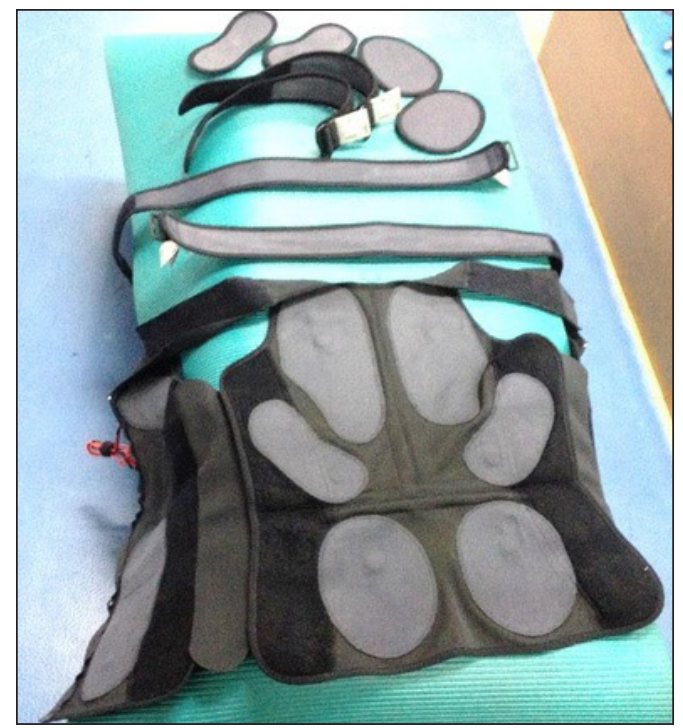

Figure 2. WB-EMS vest and belts selectable impulse intensities (0-120 mA) for each pair of electrodes. In this study, nine pairs of electrodes were applied around the players' biceps, triceps, pectoralis major, latissimus dorsi, obliques, lower back, glutes, quadriceps, and hamstring muscles. The vest comes in various sizes, ranging from XS to XL. Each player was asked to wear a vest that fit her, and the trainer made sure that the locations of all the electrodes covered all the muscles involved in the training. This group's training programme design and variables were similar to the resistance training but differed in intensity unit (electrical voltage). The players performed the electrical stimulation using manufactured biphasic rectangular wave pulse current - $85 \mathrm{~Hz}$ of a width of 350 $\mathrm{s}$, with maximal tolerance of 50 to 80 milliampere (mA), depending on week and intensity. Each single lift impulse lasted 5 seconds and was followed by a 5-second rest period. Progressive overload was also implemented in this training; all the exercises started with high repetition and low intensity (low volume) and progressed to low repetition and high intensity (high volume). However, because the loading unit was different in both training methods, the repetition maximum milliampere (RMM) was determined using previously published procedures (Hussain et al., 2016).

Prior to the electrical stimulation training, all the players in the WB-EMS group underwent three familiarisation sessions to accustom them to the electrical stimulation sensation. During the sessions, safety precautions, such as the pain feeling and technique in performing the exercises, 
were explained and checked by a qualified trainer. Then, an estimate of 1RMM of bench press and squat were conducted to determine the maximum impulse frequency that a player can contract for both exercises. The impulse frequency for the first 4 weeks of training was calculated based on the estimated 1RMM test result. Sixty-five per cent of the estimated 1RMM was set for the first week and increased by 5\% (as tolerated) for each week of training until it reached $80 \%$ of $1 \mathrm{RMM}$ at week four. At the end of the fourth week, the 3RM test was repeated to determine a new predicted 1RMM. The intensity started at $85 \%$ of the predicted 1RMM for the following week (the fifth week) and increased by $5 \%$ from the sixth week to the eighth week. If, during the eight weeks of training, a participant could complete more than the prescribed repetitions, the intensity was gradually increased. If the individual could not complete the repetitions, the load was reduced by the smallest amount possible in the subsequent exercise session. The WBEMS training group took approximately 60 minutes to complete both swing and wholebody electrical stimulation training in each exercise session.

The third group was the control (CTR) group, which also consisted of 20 players. This group performed only three sessions of swing training, similar to the TRT and WB-EMS groups. The swing practice was adopted from the study by Szymanski et al. (2009), which was able to demonstrate an increase in baseball players' performance. Coaches have also used this programme

Table 2

Whole-body electromyostimulation training programme

\begin{tabular}{|c|c|c|c|c|c|c|}
\hline \multirow[t]{2}{*}{ Variables } & \multicolumn{3}{|c|}{ Week 1 to week 4} & \multicolumn{3}{|c|}{ Week 5 to week 8} \\
\hline & \multicolumn{2}{|c|}{ Sets } & Reps & \multicolumn{2}{|c|}{ Sets } & Reps \\
\hline Warm-up & \multicolumn{2}{|c|}{2} & 10 & \multicolumn{2}{|c|}{2} & 10 \\
\hline Swing practice & \multicolumn{2}{|c|}{5} & 20 & \multicolumn{2}{|c|}{5} & 20 \\
\hline & Sets & Reps & $\%$ RMM & Sets & Reps & $\% \mathrm{RMM}$ \\
\hline Warm-up & 2 & 10 & $50-60$ & 2 & 10 & $50-60$ \\
\hline Parallel squat & 3 & $6-8$ & $65-80$ & 3 & $2-6$ & $85-90$ \\
\hline Stiff leg deadlift & 3 & $6-8$ & $65-80$ & 3 & $2-6$ & $85-90$ \\
\hline Barbell bench press & 3 & $6-8$ & $65-80$ & 3 & $2-6$ & $85-90$ \\
\hline Triceps push down & 2 & $10-12$ & $50-65$ & 2 & $8-12$ & $70-75$ \\
\hline Dumbbell biceps curl & 2 & $10-12$ & $50-65$ & 2 & $8-12$ & $70-75$ \\
\hline Seated Row & 2 & $10-12$ & $50-65$ & 2 & $8-12$ & $70-75$ \\
\hline Ball Exercise & Sets & Reps & $\% \mathrm{RMM}$ & Sets & Reps & $\% \mathrm{RMM}$ \\
\hline Hitters throw & 2 & 6 & 80 & 2 & 8 & 75 \\
\hline Standing figure 8 & 2 & 6 & 80 & 2 & 8 & 75 \\
\hline Speed rotation & 2 & 6 & 80 & 2 & 8 & 75 \\
\hline Standing side throw & 2 & 6 & 80 & 2 & 8 & 75 \\
\hline Squat and throw & 2 & 6 & 80 & 2 & 8 & 75 \\
\hline
\end{tabular}

Note. Reps=Repetitions, \%RMM= percentage of repetition maximum miliAmpere 
during softball practice daily. Although the CTR group was a control group, the participants must complete several sets of swing training. Each routine began with a warm-up consisting of two sets of ten repetitions of swinging a standard bat. The participants must then swing for 5 sets of 20 times. For the entire eight weeks, the participants trained with a standard bat. The CTR group took approximately 30 minutes to complete swing training in each exercise session.

\section{Data Analysis}

A Kolmogorov-Smirnov test for normality was performed before the analysis. First, it was determined that all parameters were normally distributed. Next, a paired sample t-test was used to compare the predicted 1RM between the groups at baseline and after week eight. Then, Levene's test was used to verify the assumption of homogenous variances. Finally, a one-way analysis of variance (ANOVA) on gain (mean difference) score was used to identify the significant difference between all training groups. All the data were analysed using SPSS 23 (IBM ${ }^{\circledR}$, Armonk, NY, USA) with a statistically significant value determined at an alpha level of $p \leq .05$.

\section{RESULTS}

After eight weeks of training, both the TRT and WB-EMS groups showed improvement in the pre-test and post-test for upper and lower body strengths with a significance value of .000 for bench press and squat tests (Table 3 ) compared to the CTR group $(p \geq .05)$.

Further analysis was conducted to determine which group showed more remarkable improvement in upper and lower body strengths. The one-way ANOVA test (Table 4) indicates a statistically significant difference between the groups in the bench press $[\mathrm{F}(2,57)=120.038, p=.000]$. The Tukey posthoc test revealed that upper body strength was significantly improved in the TRT $(7.37 \pm 1.63 \mathrm{~kg}, \mathrm{p}=.000)$ and WB-EMS $(2.37 \pm 1.72 \mathrm{~kg}, \mathrm{p}=.000)$ groups compared to the CTR group (-0.68 $\pm 1.62 \mathrm{~kg}$ ). It was pertaining to lower body strength, and a statistically significant difference was noted between the groups

Table 3

Paired sample t-test for upper and lower body strength

\begin{tabular}{lccccc}
\hline Groups & Pre mean $(\mathrm{sd})$ & Post mean $(\mathrm{sd})$ & Mean difference & t-value & $\mathrm{p}$ \\
\hline Bench Press & & & & & \\
TRT & $25.67(3.40)$ & $33.04(4.29)$ & 7.37 & 20.18 & .000 \\
WB-EMS & $24.08(3.50)$ & $26.46(3.07)$ & 2.38 & 6.18 & .000 \\
CTR & $25.10(3.02)$ & $25.33(2.88)$ & 0.23 & 1.45 & .163 \\
Squat & & & & & \\
TRT & $43.06(2.68)$ & $51.46(2.76)$ & 8.40 & 29.01 & .000 \\
WB-EMS & $42.04(2.53)$ & $46.01(2.36)$ & 3.97 & 6.47 & .000 \\
CTR & $42.71(2.15)$ & $42.83(1.93)$ & 0.11 & 0.561 & .582 \\
\hline
\end{tabular}


Table 4

Analysis of variance (ANOVA) for strength

\begin{tabular}{llccccc}
\hline & & Sum of squares & df & Mean square & F & Sig. \\
\hline \multirow{2}{*}{ Bench Press } & Between Groups & 660.789 & 2 & 330.395 & 120.038 & .000 \\
& Within Groups & 156.888 & 57 & 2.752 & & \\
\multirow{5}{*}{ Squat } & Total & 817.677 & 59 & & & \\
& Between Groups & 635.256 & 2 & 317.628 & 61.810 & .000 \\
& Within Groups & 292.910 & 57 & 5.139 & & \\
& Total & 928.166 & 59 & & & \\
\hline
\end{tabular}

Table 5

Multiple Comparison

\begin{tabular}{lccccc}
\hline Variables & (I) Group & (J) Group & Mean difference & Standard error & Sig. \\
\hline Bench Press & TRT & WB-EMS & $4.99^{*}$ & .525 & .000 \\
\multirow{2}{*}{ Squat } & & CTR & $8.05^{*}$ & .525 & .000 \\
& \multirow{2}{*}{ TRT } & WB-EMS & $4.43^{*}$ & .717 & .000 \\
& & CTR & $7.95^{*}$ & .717 & .000 \\
\hline
\end{tabular}

Note. ${ }^{*}$ The mean difference is significant at the 0.05 level

in the bench press as determined by the one-way ANOVA test $[\mathrm{F}(2,57)=61.81$, $p=.000]$. The Tukey posthoc test revealed that upper body strength was significantly improved in the TRT $(8.40 \pm 1.29 \mathrm{~kg}, \mathrm{p}=$ $.000)$ and WB-EMS $(3.97 \pm 2.74 \mathrm{~kg}, \mathrm{p}=$ $.000)$ groups compared to the CTR group $(0.45 \pm 2.49 \mathrm{~kg})$. Multiple comparison tests were conducted to identify which group elicited more remarkable changes in upper and lower body strengths. Table 5 shows a statistically significant difference between the TRT and WB-EMS $(\mathrm{p}=.000)$ groups in upper and lower body strengths. Therefore, it can be identified that the TRT group elicited more remarkable muscular strength changes than the WB-EMS group.

\section{DISCUSSION}

This study was designed to investigate the effects of superimposed WB-EMS on collegiate softball players' muscular strength. The addition of TRT and WB-EMS training sessions was found to demonstrate improvement in the players' muscular strength. It seems like the addition of three sessions of resistance training or WB-EMS after a 100-swing practice had significant effects on the performances of the 3RM bench press and squat strength tests among the collegiate female softball players. After eight weeks of training, a significant increase in the mean predicted 1RM bench press and the squat test. The increases in maximal strength are comparable to those seen in local EMS studies of trained and elite athletes after 12-28 sessions (Babault et al., 2007; Billot et al., 2010; Filipovic et al., 2011, 2012).

Despite the significant improvement in the bench press and squat scores, the improvement was marginal. While such a 
response is difficult to explain, the different improvement rates were likely related to the players' experience level. The players involved were collegiate, some of whom are at the beginning of their careers. Most of them have a beginner level of resistance training experience ( $<3$ months). Hoffman et al. (2011) suggested that experienced, resistance-trained players may need up to 2 years to achieve greater significant strength improvements. Also, most collegiate coaches were part-time coaches with possibly limited time to train players' conditioning. These coaches might have focused on improving the players' technical and tactical abilities rather than biomotor abilities, such as muscular strength. Despite the slight improvement the collegiate female softball players showed on the bench press and squat scores, all the players showed no difference in their strength scores before the intervention; they showed improvement after eight weeks of training.

Improvement of neural adaptation was one of the causes of increased muscle strength in resistance training (Suchomel et al., 2018) and full-body electromyostimulation (Gondin et al., 2006; Maffiuletti et al., 2000). Additionally, improvements in both/ either central nervous system (e.g., neuronal drive) and/or the muscle (e.g., hypertrophy) explained the strength gains following training. Although there have been no EMG or cross-sectional area measurements in the current study to confirm that the strength improvement occurred at the muscle or central nervous system, the EMS training was assumed to have resulted in neural adaptation rather than muscle adaptation. Only minor changes were reported in a cross-sectional area (CSA) during the first three to eight weeks of resistance and electrical stimulation training (Aagaard et al., 2002; Aldayel, 2010). A study by Narici et al. (1989) was one of the earliest studies measuring the changes in CSA, maximum voluntary contraction (MVC), and neural activation in quadriceps muscle after eight weeks of resistance training. The study showed significant improvement in all three measurements. However, CSA improvement was reported below $50 \%$ compared to MVC and neural activation, which was measured using electromyography. This observation is also in line with Moritani and Devries's (1980) study. Therefore, it would be reasonable to expect that the increase in muscle strength found in this study could improve neural activation compared to the CSA. Additionally, electrical stimulation was found to activate the nerve's intramuscular branches rather than the muscle fibres directly (Aldayel, 2010).

Collins (2007) found that by the transcutaneous peripheral nerve stimulation, direct muscle electrostimulation causes muscle contraction, induced directly by depolarising motoneurons or indirectly by depolarising sensory afferents. The stimulation recruits motor units differently from physiological muscle recruitment during voluntary contraction, which may explain the strength gain observed following electrostimulation training in healthy subjects. Electrostimulation was frequently thought to recruit motor units in the reverse 
order of voluntary drive, contradicting Hennemann's “size principle". According to this principle, slow motor units associated with small-diameter motoneuron axons are active before fast motor units associated with larger-diameter axons. In contrast to voluntary contraction, the current view implies that recruitment does not occur in a synchronised pattern (Dehail et al., 2008). The electrode surface, location, and type, as well as the stimulated muscle, all appear to affect the conductive volume and current density, which affects the recruitment pattern. When repeated electrical stimulations are used, such as during muscle training, an adaptation of muscle physiology is observed in healthy subjects. The cross-sectional area of type-I muscle fibres or the entire muscle group that was trained has increased (Gondin et al., 2006; Herrero et al., 2006). Such was associated with an increase in the IIa isoform of myosin's heavy chains (Maffiuletti et al., 2006) and appeared to be greater when the voluntary contraction was combined with stimulation (Sanchez et al., 2005). These changes are dependent on the type of stimulation used and may be associated with an increase in a trained muscle's maximal strength and electrical activity (Gondin et al., 2006; Maffiuletti et al., 2006; Sanchez et al., 2005).

In addition, both the training groups received a training programme that operates on the theory of progressive overload, which is one of the factors that could improve an athlete's fitness performance. Progressive overload is a fundamental strength-training principle achieved by varying variables, such as intensity, volume, rest times, and frequency (Whaley et al., 2020). The training load (intensity) in the current study was started slowly and gradually increased until it reached 90 per cent of $1 \mathrm{RM}$ at the end of the exercise. Progressive overload mechanism was shown to affect one's hormonal, acute metabolic, neural, and cardiovascular responses to exercises (Kraemer \& Ratamess, 2005; Kraemer et al., 2006; Ratamess et al., 2009, Whaley et al., 2020).

Increased stress on skeletal muscle eventually led to improvements in muscle size increment and modification of contractile characteristics (Bird et al., 2005). Overload and progressive principles were also found to lead to muscular strength adjustment and increased dynamic force. This finding also supports the previous studies (Szymanski et al., 2009; Szymanski et al., 2007a; Szymanski et al., 2007b), which found dynamic strength improvement related to the implementation of the progressive overload principle.

The current study also discovered that WB-EMS provided safe training with no detrimental effect on players' performance. The WB-EMS approach can also be an alternative training for improving players' performance as the training consumes less training time. Although the current study showed improvement in dynamic strength, more studies are required to identify the underlying effects of WB-EMS on athlete's sports performance at different training frequencies, intensities, and duration of training. Although this study can reach 
some conclusions about the effectiveness of both the TRT and WB-EMS training, the underlying mechanism of the training was not fully explored. Therefore, a conclusion can be drawn that TRT has improved muscular strength, but no conclusive evidence was derived on the best training mode. A further investigation related to electromyography (EMG) analysis, particularly at the cell level, is needed to clarify the effects of the possible underlying mechanisms of WB-EMS training. Such studies could help justify the changes that occur in the human body after WB-EMS training.

\section{CONCLUSION}

The present study demonstrated that inducing TRT and WB-EMS interventions to regular softball training for eight weeks resulted in increased muscular strength among the softball players. The findings also note that among the two training modes conducted in this study, TRT demonstrated a more considerable improvement in both upper and lower body strengths compared to WB-EMS.

\section{ACKNOWLEDGEMENTS}

We gratefully acknowledge the support of Faculty of Sports Science University Teknologi MARA gymnasium and Miha BodyTec (United Lifestyle). None of the authors has any conflict of interest. We are also grateful for the grant from Research Management Institute (RMI): 600-RMI/ MyRA 5/3/LESTARI (32/2016).

\section{REFERENCES}

Aagaard, P., Simonsen, E. B., Andersen, J. L., Magnusson, P., \& Dyhre-Poulsen, P. (2002). Neural adaptation to resistance training: Changes in evoked V-wave and H-reflex responses. Journal of Applied Physiology, 92(6), 2309-2318. https://doi.org/10.1152/japplphysiol.01185.2001

Aldayel, A. A. (2010). Comparison of acute physiological effects between alternating current and pulsed current electrical muscle stimulation [Doctoral dissertation, Edith Cowan University]. Edith Cowan University Publishing. https:// ro.ecu.edu.au/theses/131/

Babault, N., Cometti, G., Bernardin, M., Pousson, M., \& Chatard, J.-C. (2007). Effects of electromyostimulation training on muscle strength and power of elite rugby players. Journal of Strength and Conditioning Research, 21(2), 431-437. https://doi.org/10.1519/00124278200705000-00025

Baechle, T. R., \& Earle, R. W. (Eds.). (2008). Essentials of strength training and conditioning. Human Kinetics.

Bhave, P. T. A. (2021). Neuromuscular electrical stimulation increases muscle strength, reduces pain, and improves functional recovery. International Journal Orthopaedic Sports Medicine, 2(1), 1007.

Billot, M., Martin, A., Paizis, C., Cometti, C., \& Babault, N. (2010). Effects of an electrostimulation training program on strength, jumping, and kicking capacities in soccer players. The Journal of Strength \& Conditioning Research, 24(5), 1407-1413. https://doi. org/10.1519/JSC.0b013e3181d43790

Bird, S. P., Tarpenning, K. M., \& Marino, F. E. (2005). Designing resistance training programmes to enhance muscular fitness. Sports Medicine, 35(10), 841-851. https://doi. org/10.2165/00007256-200535100-00002 
Collins, D. F. (2007). Central contributions to contractions evoked by tetanic neuromuscular electrical stimulation. Exercise and Sport Sciences Reviews, 35(3), 102-109. https://doi. org/10.1097/jes.0b013e3180a0321b

Dehail, P., Duclos, C., \& Barat, M. (2008). Electrical stimulation and muscle strengthening. Annales de Réadaptation et de Médecine Physique, 51(6), 441-451. https://doi.org/10.1016/j. annrmp.2008.05.001

DeRenne, C., Ho, K. W., \& Murphy, J. C. (2001). Effects of general, special, and specific resistance training on throwing velocity in baseball: A brief review. The Journal of Strength \& Conditioning Research, 15(1), 148-156. https:// doi.org/10.1519/00124278-200102000-00026

Earle, R. W., Baechle, T. R., \& National Strength \& Conditioning Association. (2004). NSCA's essentials of personal training. Human Kinetics.

Filipovic A., DeMarees M., Grau M., Hollinger A., Seeger B., Schiffer T., Bloch W., Gehlert S. (2019). superimposed whole-body electrostimulation augments strength adaptations and type II myofiber growth in soccer players during a competitive season. Frontiers in Physiology, 10, 1187. https://doi.org/10.3389/ fphys.2019.01187

Filipovic, A., Grau, M., Kleinöder, H., Zimmer, P., Hollmann, W., \& Bloch, W. (2016). Effects of a whole-body electrostimulation program on strength, sprinting, jumping, and kicking capacity in elite soccer players. Journal of Sports Science \& Medicine, 15(4), 639-648.

Filipovic, A., Kleinöder, H., Dörmann, U., \& Mester, J. (2011). Electromyostimulation - a systematic review of the influence of training regimens and stimulation parameters on effectiveness in electromyostimulation training of selected strength parameters. The Journal of Strength \& Conditioning Research, 25(11), 3218-3238. https://doi.org/10.1519/JSC.0b013e318212e3ce
Filipovic, A., Kleinöder, H., Dörmann, U., \& Mester, J. (2012). Electromyostimulation-a systematic review of the effects of different electromyostimulation methods on selected strength parameters in trained and elite athletes. The Journal of Strength \& Conditioning Research, 26(9), 2600-2614. https://doi. org/10.1519/JSC.0b013e31823f2cd1

Gondin, J., Guette, M., Ballay, Y., \& Martin, A. (2006). Neural and muscular changes to detraining after electrostimulation training. European Journal of Applied Physiology, 97(2), 165-173. https://doi. org/10.1007/s00421-006-0159-z

Gregory, C. M., \& Bickel, C. S. (2005). Recruitment patterns in human skeletal muscle during electrical stimulation. Physical Therapy, 85(4), 358-364. https://doi.org/10.1093/ptj/85.4.358

Herrero, J. A., Izquierdo, M., Maffiuletti, N. A., \& Garcia-Lopez, J. (2006). Electromyostimulation and plyometric training effects on jumping and sprint time. International Journal of Sports Medicine, 27(07), 533-539. https://doi. org/10.1055/s-2005-865845

Hoffman, J. R., Ratamess, N. A., \& Kang, J. (2011). Performance changes during a college playing career in NCAA division III football athletes. The Journal of Strength \& Conditioning Research, 25(9), 2351-2357. https://doi: 10.1519/ JSC.0b013e31821743df

Hussain, R. N. J. R., Kee, K. M., Razman, R., Ismail, S. I., Shari, M., \& Ideris, N. M. (2016). Relationship between electromyostimulation and free weight exercises in multiple repetition maximum strength test. In International Conference on Movement, Health and Exercise (pp. 83-87). Springer, Singapore. https://doi. org/10.1007/978-981-10-3737-5_17

Jubeau, M., Sartorio, A., Marinone, P. G., Agosti, F., Van Hoecke, J., Nosaka, K., \& Maffiuletti, N. A. (2008). Comparison between voluntary and stimulated contractions of the quadriceps 
femoris for growth hormone response and muscle damage. Journal of Applied Physiology, 104(1), 75-81. https://doi.org/10.1152/ japplphysiol.00335.2007

Kemmler, W., Schliffka, R., Mayhew, J. L., \& von Stengel, S. (2010). Effects of whole-body electromyostimulation on resting metabolic rate, body composition, and maximum strength in postmenopausal women: The training and electrostimulation trial. The Journal of Strength \& Conditioning Research, 24(7), 1880-1887. https://doi.org/10.1519/JSC.0b013e3181ddaeee

Kemmler, W., \& von Stengel, S. (2013). Whole-body electromyostimulation as a means to impact muscle mass and abdominal body fat in lean, sedentary, older female adults: Subanalysis of the TEST-III trial. Clinical Interventions in Aging, 8, 1353. https://doi.org/10.2147/CIA.S52337

Kemmler, W., Von Stengel, S., Schwarz, J., \& Mayhew, J. L. (2012). Effect of whole-body electromyostimulation on energy expenditure during exercise. The Journal of Strength \& Conditioning Research, 26(1), 240-245. https:// doi.org/10.1519/JSC.0b013e31821a3a11

Kemmler, W., Weissenfels, A., Willert, S., Shojaa, M., von Stengel, S., Filipovic, A., Kleinöder, H., Berger, J., \& Fröhlich, M. (2018). Efficacy and safety of low frequency whole-body electromyostimulation (WB-EMS) to improve health-related outcomes in non-athletic adults. A systematic review. Frontiers in Physiology, 9, 573. https://doi.org/10.3389/fphys.2018.00573

Kraemer, W. J., \& Ratamess, N. A. (2005). Hormonal responses and adaptations to resistance exercise and training. Sports Medicine, 35(4), 339-361. https://doi.org/10.2165/00007256-20053504000004

Kraemer, W. J., Spiering, B. A., Volek, J. S., Ratamess, N. A., Sharman, M. J., Rubin, M. R., French, D. N., Silvestre, R., Hatfield, D. L., Van Heest, J. L., Vingren, J. L., Judelson, D. A., Deshenes,
M. R., \& Maresh, C. M. (2006). Androgenic responses to resistance exercise: Effects of feeding and L-carnitine. Medicine \& Science in Sports \& Exercise, 38(7), 1288-1296. https:// doi.org/10.1249/01.mss.0000227314.85728.35

Ludwig, O., Berger, J., Schuh, T., Backfisch, M., Becker, S., \& Fröhlich, M. (2020). Can a superimposed whole-body electromyostimulation intervention enhance the effects of a 10 -week athletic strength training in youth elite soccer players?. Journal of Sports Science \& Medicine, 19(3), 535-546.

Maffiuletti, N. A., Gometti, C., Amiridis, I. G., Martin, A., Pousson, M., \& Chatard, J. C. (2000). The effects of electromyostimulation training and basketball practice on muscle strength and jumping ability. International journal of sports medicine, 21(06), 437-443. https://doi. org/10.1055/s-2000-3837

Maffiuletti, N. A., Zory, R., Miotti, D., Pellegrino, M. A., Jubeau, M., \& Bottinelli, R. (2006). Neuromuscular adaptations to electrostimulation resistance training. American Journal of Physical Medicine \& Rehabilitation, 85(2), 167-175. https://doi.org/10.1097/01. phm.0000197570.03343.18

Milanovich, M., \& Nesbit, S. M. (2014). A threedimensional kinematic and kinetic study of the college-level female softball swing. Journal of Sports Science \& Medicine, 13(1), 180.

Moritani, T., \& Devries, H. A. (1980). Potential for gross muscle hypertrophy in older men. Journal of Gerontology, 35(5), 672-682. https://doi. org/10.1093/geronj/35.5.672

Moro, T., Marcolin, G., Bianco, A., Bolzetta, F., Berton, L., Sergi, G., \& Paoli, A. (2020). Effects of 6 weeks of traditional resistance training or high intensity interval resistance training on body composition, aerobic power and strength in healthy young subjects: A randomized parallel trial. International Journal of Environmental 
Research and Public Health, 17(11), 4093. https://doi.org/10.3390/ijerph17114093

Narici, M. V., Roi, G. S., Landoni, L., Minetti, A. E., \& Cerretelli, P. (1989). Changes in force, cross-sectional area and neural activation during strength training and detraining of the human quadriceps. European Journal of Applied Physiology and Occupational Physiology, 59(4), 310-319. https://doi.org/10.1007/BF02388334

Nosaka, K., Aldayel, A., Jubeau, M., \& Chen, T. C. (2011). Muscle damage induced by electrical stimulation. European Journal of Applied Physiology, 111(10), 2427-2437. https://doi. org/10.1007/s00421-011-2086-x

Nunes, J. P., Grgic, J., Cunha, P. M., Ribeiro, A. S., Schoenfeld, B. J., de Salles, B. F., \& Cyrino, E. S. (2021). What influence does resistance exercise order have on muscular strength gains and muscle hypertrophy? A systematic review and meta-analysis. European Journal of Sport Science, 21(2), 149-157. https://doi.org/10.108 $0 / 17461391.2020 .1733672$

Park, J., Hong, C., \& Cheon, W. (2020). Investigation on the relation among the body composition, physical fitness, and field test of female softball players. International Journal Of Protection, Security \& Investigation, 5(1), 1-13. http://doi. org/10.22471/protective.2020.5.1.01

Ratamess, N., Alvar, B., Evetoch, T., Housh, T., Kibler, W., Kraemer, W., \& Triplett, N. T. (2009). Progression models in resistance training for healthy adults [ACSM position stand]. Medicine \& Science in Sports \& Exercise, 41(3), 687-708. https://doi.org/10.1249/mss.0b013e3181915670

Ruivo, R., Carita, A., \& Pezarat-Correia, P. (2016). Effects of a 16-week strength-training program on soccer players. Science \& Sports, 31(5), e107-e113. https://doi.org/10.1016/j. scispo.2016.02.008

Sanchez, B. R., Puche, P. P., \& González-Badillo, J. J. (2005). Percutaneous electrical stimulation in strength training: An update. The Journal of Strength \& Conditioning Research, 19(2), 438-448. https://doi.org/10.1519/00124278200505000-00033

Stöllberger, C., \& Finsterer, J. (2019). Side effects of whole-body electro-myo-stimulation. Wiener Medizinische Wochenschrift, 169(7), 173-180. https://doi.org/10.1007/s10354-018-0655-x

Stone, M. H., Potteiger, J. A., Pierce, K. C., Proulx, C. M., O’bryant, H. S., Johnson, R. L., \& Stone, M. E. (2000). Comparison of the effects of three different weight-training programs on the one repetition maximum squat. The Journal of Strength \& Conditioning Research, 14(3), 332-337. https://doi.org/10.1519/00124278200008000-00015

Strasunskas, D. (2020). Impact of strength training on basketball athletes [Master's dissertation, University of Iceland] University of Iceland Publishing. https://skemman.is/ bitstream/1946/36689/1/Impact\%20of\%20 strength $\% 20$ training $\% 20$ on $\% 20$ basketball $\% 20$ athletes $\% 20$ pdf..pdf

Stricker, P. R., Faigenbaum, A. D., \& McCambridge, T. M. (2020). Resistance training for children and adolescents. Pediatrics, 145(6). https://doi. org/10.21037/tp.2017.04.01

Stuempfle, K. J., Crawford, B. E., Petrie, D. F., \& Kirkpatrick, M. T. (2004). Effect of hydro resistance training on bat velocity. Journal of Exercise Physiology Online, 7(2), 63-69.

Suchomel, T. J., Nimphius, S., Bellon, C. R., \& Stone, M. H. (2018). The importance of muscular strength: training considerations. Sports Medicine, 48(4), 765-785. https://doi. org/10.1007/s40279-018-0862-z

Sugimoto, D., Mattacola, C. G., Bush, H. M., Thomas, S. M., Foss, K. D. B., Myer, G. D., \& Hewett, T. E. (2017). Preventive neuromuscular training for young female athletes: Comparison of coach and athlete compliance rates. Journal 
of Athletic Training, 52(1), 58- 64. https://doi. org/10.4085/1062-6050-51.12.20

Szymanski, D. J., DeRenne, C., \& Spaniol, F. (2009). Contributing factors for increased bat swing velocity. The Journal of Strength \& Conditioning Research, 23(4), 1338-1352. https://doi.org/10.1519/JSC.0b013e318194e09c

Szymanski, D. J., McIntyre, J., Szymanski, J., Bradford, T., Schade, R., Madsen, N., \& Pascoe, D. (2007a). Effect of torso rotational strength on angular hip, angular shoulder, and linear bat velocities of high school baseball players. The Journal of Strength \& Conditioning Research, 21(4), 1117-1125. https://doi. org/10.1519/00124278-200711000-00024

Szymanski, D. J., Szymanski, J., Bradford, T., Schade, R., \& Pascoe, D. (2007b). Effect of twelve weeks of medicine ball training on high school baseball players. The Journal of Strength \& Conditioning Research, 21(3), 894-901. https:// doi.org/10.1519/00124278-200708000-00041

Szymanski, D. J., Szymanski, J. M., Molloy, J. M., \& Pascoe, D. D. (2004). Effect of 12 weeks of wrist and forearm training on high school baseball players. The Journal of Strength \& Conditioning Research, 18(3), 432-440. https:// doi.org/10.1519/00124278-200408000-00007

Whaley, O., Larson, A., \& DeBeliso, M. (2020). Progressive movement training: An analysis of its effects on muscular strength and power development. Medicine and Science in Sports and Exercise, 52(17), 210-211. https://doi. org/10.1249/01.mss.0000675840.15637.df 
